\begin{tabular}{|l|l|}
\hline 2. To: (Receiving Organization) & 3. From: (Originat ing Organization) \\
Engineering Administration & FFTF ASEE 18240 \\
\hline 5. Proj./Prog./Dept./Div.: & $\begin{array}{l}\text { 6. Design Authority/ Design Agent/Cog } \\
\text { Engr.: } \\
\text { F-031 }\end{array}$ \\
\hline
\end{tabular}

8. Originator Remarks:

Ladder Logic Diagrams for the Sodium Storage Facility PLC's

$$
\mathrm{N} / \mathrm{A}
$$

9. Equip./Component No.: $\mathrm{C}-3005$

10. System/Bldg./Facility: S93B/402/SSF

11. Receiver Remarks: 11A. Design Basel ine Document? [X] Yes [] No

12. Major Assm. Dwg. No.:

H-4-302426

13. Permit/Permit Application No.:

14. Required Response Date:

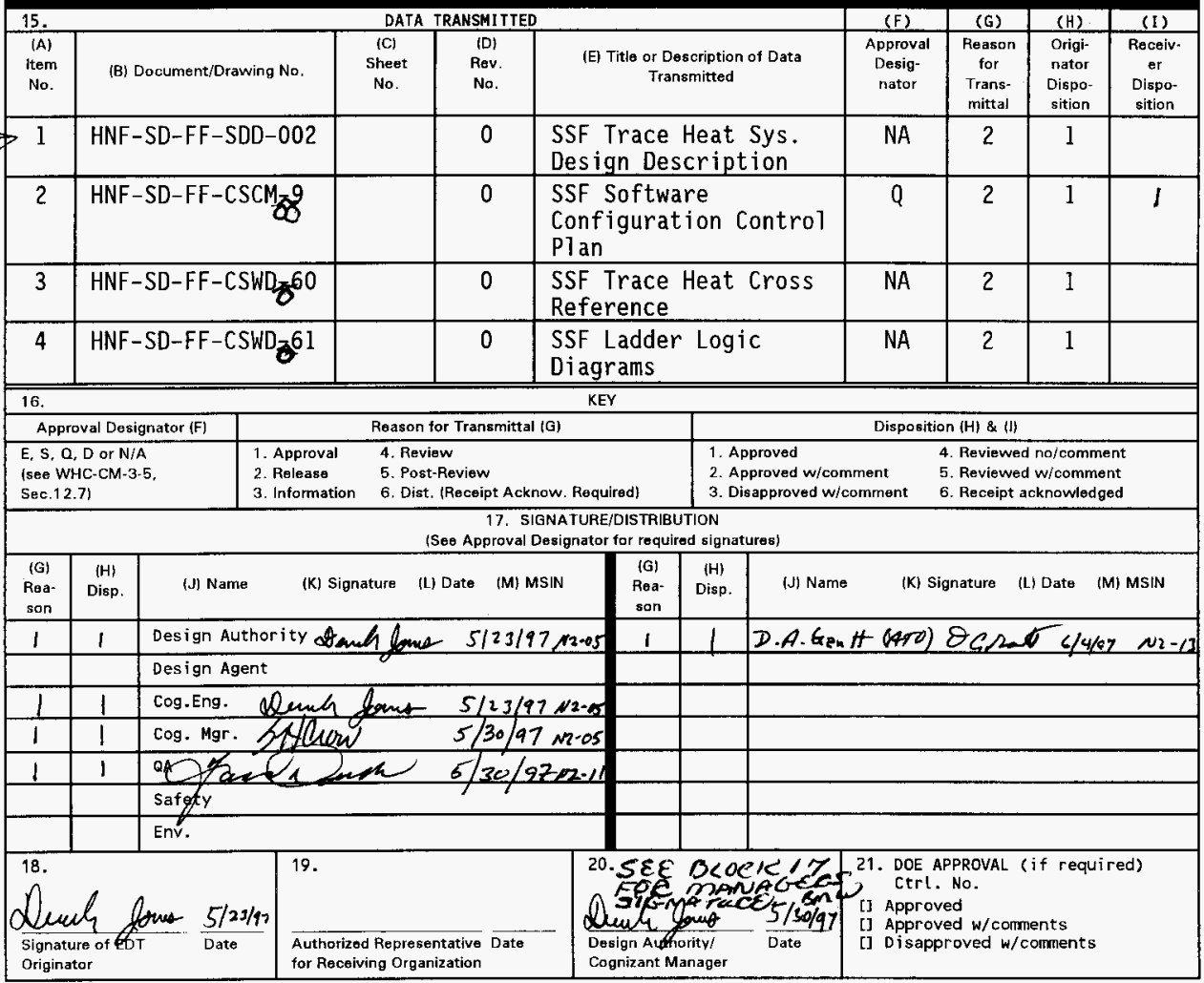




\section{Sodium Storage Facility Trace Heat System Design Description}

Derek D. Jones

B \& W Hanford Company, Richland, WA 99352

U.S. Department of Energy Contract DE-AC06-96RL13200

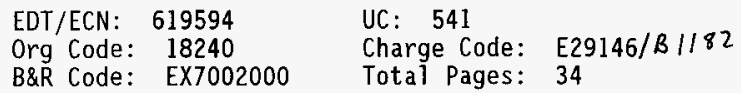

Key Words: Sodium, SSF, Trace Heat, PLC, Computer

Abstract: This document describes the SSF PLC Ladder Logic, Cross references, and the software that was used to control the amount of power applied to the SSF Trace Heated components.

At the time that this document was created:

INTERCHANGE' ${ }^{\text {M }}$, and APS ${ }^{\text {TM }}$ are Trademarks of Rockwell Software Inc.

SLC $5 / 04^{\mathrm{TM}}$ is a Trademark of Allen-Bradley Company, Inc.

DIN-A-MITE is a Trademark of Watlow Electric Manufacturing Company.

Microsoft Windows ${ }^{\circledR}$, and MS-DOS ${ }^{\circledR}$ are registered trademarks and Microsoft EXCEL $^{\text {TM }}$ is a Trademark of Microsoft Corporation.

Intellution is a registered trademark, FIX MMI ${ }^{\mathrm{IM}}$ is a trademark of Intellution Inc.

TRADEMARK DISCLAIMER. Reference herein to any specific commercial product, process, or service by trade name, trademark, manufacturer, or otherwise, does not necessarily constitute or imply its endorsement, recommendation, or favoring by the United States Government or any agency thereof or its contractors or subcontractors.

Printed in the United States of America. To obtain copies of this document, contact: Document Control Services, P.O. Box 950, Mailstop H6-08, Richland WA 99352, Phone (509) 372-2420; Fax (509) 376-4989.
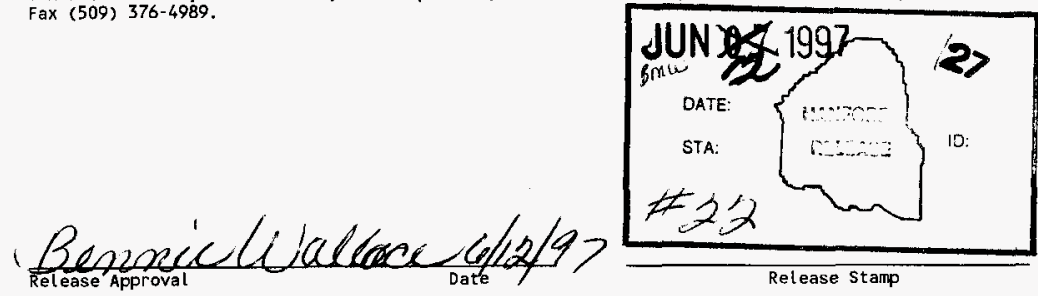
This document describes the Trace Heat Monitoring and Control system for the Sodium Storage Facility (SSF). The SSF is designed for the transfer of molten sodium metal from the Fast Flux Test Facility (FFTF) to the storage tanks located in SSF. Sodium freezes at a nominal temperature of $98^{\circ} \mathrm{C}\left(208^{\circ} \mathrm{F}\right)$. This system is used to heat the sodium piping and storage tanks to a temperature of $163{ }^{\circ} \mathrm{C}\left(325^{\circ} \mathrm{F}\right)$ and tested up to an average temperature $205^{\circ} \mathrm{C}\left(400^{\circ} \mathrm{F}\right)$, using surface mounted electric resistance heaters. This system is designated as system S93B in the FFTF Job Control System (JCS) and referred to as a System Control and Data Acquisition (SCADA) system in the original vendor information.

\subsection{SYSTEM SUMMARY DESCRIPTION}

\subsection{System Description}

The Heater Control System is based on a Allen-Bradley SLC 500 series Programmable Logic Controller (PLC) and Watlow SCR based power control modules.

The operator interface to the PLC will be via $486 \mathrm{DX}$ micro computer (PC). The software used is the Intellution FIX ${ }^{\mathrm{TM}}$ (Fully Integrated Control System) DMACS ${ }^{\mathrm{TM}}$ (Distributed Automation and Control Software) running in the Microsoft Windows environment. The Allen-Bradley L/O Driver Software is called "INTERCHANGETM." MICROSOFT EXCELTM was used to create the DataBase or what Intellution calls the Driver Image Table. The Driver Image Table establishes a Shared Memory area that is used to pass information between the PC and the PLC. MICROSOFT EXCEL $^{\mathrm{TM}}$ can also be used for processing the Historical Data Collection files exported by the Intellution software.

This control scheme allows operational changes to be made with minimal knowledge of the Intellution software. The temperature setpoints can be selected and then changed to the desired setpoint using screens that were custom designed for the SSF.

\subsection{System Boundaries}

Mechanically, the heaters and thermocouple sensors used by this system are strapped or cemented onto the outside of sodium piping and storage tanks and do not penetrate the ASME boundaries. The majority of the control system hardware (except the PC) is physically located in Control Panels C-3001, C-3002, C-3003, C-3004, and C-3005 which are located in the SSF electrical equipment room (room 104).

Electrically, B-3001, B-3011, B-3012, and B-3013 supply power to and are the boundaries between this system and the SSF Electrical Distribution system (System S12). See drawings H-4-30245I and H-4-302452 for morc information.

The valves and piping heaters use single phase power (each breaker comes off of one phase and supplies a heater zone). The tank heater zones are three phase (each circuit breaker is one phase and the three breakers for each heater zone are ganged together).

Power to the control system is through the Uninterruptible Power Supply (B-301 I-2). The Uninterruptible Power Supply (UPS) is located in Room 104 in C-3005. It supplies power to the PLC and an outlet for the computer in room 202 to ride out a power loss of less than one hour. The UPS also protects the PLC and computer from power surges. 
Besides the equipment listed in section 2.2 above, this system also provides indication of the state of the four SSF Rupture Disk Pressure Switches (PSH for Pressure Switch High) located in the SSF cover gas control system.

\subsection{System Classification}

This system is a Safety Class 4/Impact Level NA or non-safety, non-environmental, and not a quality affecting system. However, the Ground Fault Detection relays in this system are installed to protect the Sodium Piping from an arcing short circuit that could result in a sodium spill and fire if the ground fault is not detected soon enough.

\subsection{FUNCTION AND DESIGN REQUIREMENTS}

\subsection{Functions}

The function of this system is to preform initial preheat prior to FFTF sodium drain operations and to perform a melt-out of solid sodium for transfer to a yet to be built sodium reaction facility

When the systems are heated for the first time, a sequential heat up will not be required because the sodium systems are empty. The first tank will be heated to operating temperature and then the fill and drain header piping and valves will be heated. While the first tank is being filled with sodium, a second tank can be heated.

Drawing H-4-302444 presents the overall layout of the sodium storage facility fill and drain header. Drawing H-4-302445 shows the tank trace heater zone layout.

\subsection{System Design Requirements}

This system was designed for basically two operational periods. The first time would be right after the facility was built to drain the sodium from FFTF to the tanks in the SSF. The second time would be to melt the sodium filled tanks and slowly send the sodium out to a reaction facility in order to turn the sodium into sodium hydroxide or sodium carbonate.

\subsubsection{Operability requirements}

Operations procedure SN-93.15-2 has been prepared assuming that the systems will be electrically shutdown and at ambient temperature. But the procedure also was created in a sequential melt-out format so that the procedure could be used in the event the systems are shutdown between the Secondary and Primary sodium drain evolutions. Because this software is object oriented, $\mathrm{SN}-93.15-2$ does not fully describe the operation of all software options.

It is assumed that the operators will only use the automatic mode of operation for the Trace Heat Zones. In the automatic mode of operation, the software provides heat-up rate limitations. Under normal circumstances that is all that will be required. However, manual control is also available. In the manual mode of operation. the operator is responsible for heat-up rate. The manual mode allows the operator to simply set in the percent output that he or she requires from the SCRs.

Trend Graphs and Help Windows can also be created or changed as required to meet the requirements of the FFTF operations organization. 


\subsubsection{System set points}

With the system shutdown as it is now, and will be most of the time, the low temperature alarms are set at $10^{\circ} \mathrm{F}$ or $20^{\circ} \mathrm{F}$, and the high temperature alarms are set at $100^{\circ} \mathrm{F}$. Their only purpose is to detect an inadvertent heat up. The computer was left on after acceptance testing primarily to monitor the PSH alarms. When transfer operations are not in progress, the most likely cause of PSH alarm will be due to the expansion of gas trapped between the rupture disc and the pressure relief valves. This gas space was pressurized to perform relief valve testing. Even after this gas pressure is bled off, it can expand due to ambient temperature changes.

When the system is in operation and the tanks are hot, the setpoints can be set at any temperature between $148^{\circ} \mathrm{C}$ and $254^{\circ} \mathrm{C}\left(300^{\circ} \mathrm{F}\right.$ and $\left.490^{\circ} \mathrm{F}\right)$. The $254^{\circ} \mathrm{C}$ limit is based on not allowing OMEGABOND 200 cement to melt. At the end of the project, we could not verify that the vendors did not use OMEGABOND 200, but we believe that they mostly used OMEGABOND 300 which does not melt until $871^{\circ} \mathrm{C}\left(1600^{\circ} \mathrm{F}\right)$. For this reason, if insulation is removed for some reason and it is verified that OMEGABOND 200 (which is black in color) was not used, then temperatures up to $300^{\circ} \mathrm{C}\left(575^{\circ} \mathrm{F}\right)$ are acceptable.

\subsubsection{System instrumentation and alarms}

The trace heat system consists of a computer that provides the interface between the operator and the trace heal system components:

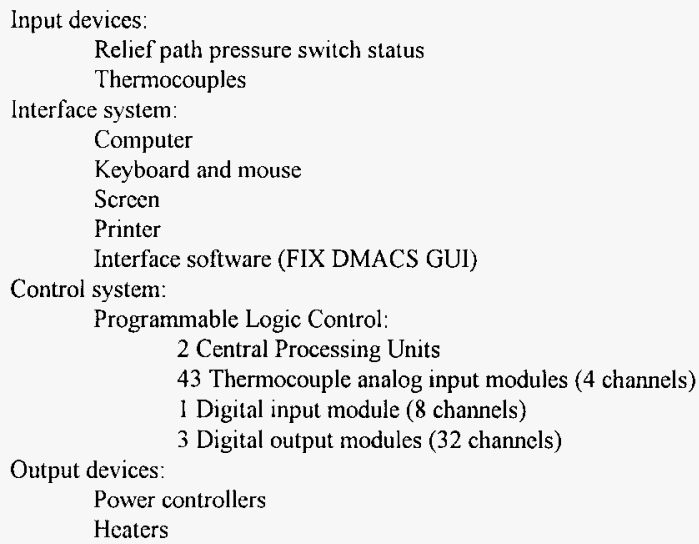

Drawing H-4-302501 is a Block Diagram of the trace heat system. It shows the relationship of each part of the system from the input devices, the interface and control system and to the output devices.

High temperature, Low Temperature, PSH contact closure, and Hardware alarms are provided as described in SA-93-15-2.

\subsubsection{System interlocks}

A software interlock prevents heating two Sodium Storage tanks simultaneously. 


\subsubsection{Maintenance requirements}

This system is designed to be basically free from any periodic maintenance requirements.

\subsubsection{External hazards}

This system can be damaged by water leakage into room 104, by extreme ambient temperatures, or by fire. The control cabinets in this room are not spray tight. Water entering these cabinets can leave deposits that can alter the physical characteristics (resistances) of the circuits inside these cabinets. These deposits can create alternate paths for current flow that can short power to devices that are not meant to handle the 120 or $480 \mathrm{VAC}$ power that is present in these cabinets

A good overall set of ambient temperature limits for the SSF electrical equipment (room 104) is 0 to $25^{\circ} \mathrm{C}\left(32\right.$ to $\left.77^{\circ} \mathrm{F}\right)$. If air conditioning is lost in the summertime, the PLC and PC should be shut down. The system will not be damaged as long as the room temperature does not exceed $40^{\circ} \mathrm{C}$ $\left(104{ }^{\circ} \mathrm{F}\right)$

All of the equipment is designed to be in 0 to $90 \%$ relative humidity with no condensing occurring on or within the cabinets.

For long term storage of the equipment contained in SSF room 104, the temperature range should be $0^{\circ}$ to $40^{\circ} \mathrm{C}\left(32^{\circ}\right.$ to $\left.104^{\circ} \mathrm{F}\right)$. The limiting piece of equipment is the battery that is inside the $\mathrm{C}-3005$ UPS. The temperature limits for other equipment is listed primarily for informational purposes to help determine when the calibration of the equipment becomes questionable.

The Allen Bradley PLC and the modules for this PLC that we are using have an operating temperature range of 0 to $60^{\circ} \mathrm{C}\left(32\right.$ to $\left.140^{\circ} \mathrm{F}\right)$ and a storage temperature rating of -40 to $+86{ }^{\circ} \mathrm{C}$ $\left(-40^{\circ} \mathrm{to}+185^{\circ} \mathrm{F}\right)$.

The Watlow SCRs are rated to operate from 0 to $80^{\circ} \mathrm{C}\left(32\right.$ to $\left.176^{\circ} \mathrm{F}\right)$ at their rated maximum current.

The microprocessor for the $\mathrm{PC}$ is rated for operation at an ambient temperature of between 0 to $50^{\circ} \mathrm{C}\left(32\right.$ to $\left.122^{\circ} \mathrm{F}\right)$.

\subsubsection{Structural requirements}

This equipment is designed to be indoors with temperatures controlled as specified above. The major space requirements for this equipment is as follows:

\begin{tabular}{|c|c|c|c|c|c|}
\hline & C-300I & C-3002 & C-3003 & C-3004 & $\mathrm{C}-3005$ \\
\hline $\begin{array}{r}\text { Height inches } \\
\text { Millimeters }\end{array}$ & $\begin{array}{l}86.61 \\
2200\end{array}$ & $\begin{array}{l}86.61 \\
2200\end{array}$ & $\begin{array}{l}86.61 \\
2200\end{array}$ & $\begin{array}{l}86.61 \\
2200\end{array}$ & $\begin{array}{l}86.61 \\
2200\end{array}$ \\
\hline $\begin{array}{l}\text { Width } \begin{array}{r}\text { inches } \\
\text { Millimeters }\end{array}\end{array}$ & $\begin{array}{l}47.24 \\
1200\end{array}$ & $\begin{array}{l}39.37 \\
1000\end{array}$ & $\begin{array}{l}39.37 \\
1000\end{array}$ & $\begin{array}{l}47.24 \\
1200\end{array}$ & $\begin{array}{l}31.5 \\
800\end{array}$ \\
\hline $\begin{array}{l}\text { Depth inches } \\
\text { Millimeters }\end{array}$ & $\begin{array}{l}19.61 \\
500\end{array}$ & $\begin{array}{l}19.61 \\
500\end{array}$ & $\begin{array}{l}19.61 \\
500\end{array}$ & $\begin{array}{l}19.61 \\
500\end{array}$ & $\begin{array}{l}19.61 \\
500\end{array}$ \\
\hline
\end{tabular}

HNF-SD-FF-SDD-002 Rev. 0

Page 4 
The computer is small footprint medium tower case which is $190 \mathrm{~mm}$ (W) X $406 \mathrm{~mm}$ (H) X $432 \mathrm{~mm}$ (D) (7.5" X 16" X 17"). An additional $127 \mathrm{~mm}\left(5^{\prime \prime}\right)$ is needed to be added to the depth to allow room for the software key and printer cable.

The computer monitor has a 20 inch screen with full physical dimensions as follows: $495 \mathrm{~mm}$ (W) X $500 \mathrm{~mm}(\mathrm{H}) \times 508 \mathrm{~mm}$ (D) (19.5" X 19.7" X 20.0").

The system printer is $406 \mathrm{~mm}$ (W) X $153 \mathrm{~mm}$ (H) X $305 \mathrm{~mm}$ (D) (16" X 6" X 12"). Then add another $77 \mathrm{~mm}\left(3^{\prime \prime}\right)$ in width to allow for connecting the printer cable.

\subsubsection{Inspection requirements}

There are no periodic inspection requirements for this system. Initial calibration, grooming, and alignment of this system was performed by WHC-SD-F031-ATP-004.

\subsubsection{Designer options}

During the preliminary design phase of the SSF project, brainstorming sessions were held. Immersion heaters for these tanks were ruled out because the cost of reestablishing the ASME boundary of the tanks was seen as being unnecessarily costly. Induction heating was discussed but did not seem practical for both the tanks and the piping. The Cal Rod piping heaters used in FFTF were designed to create an oven and induce even convective heating around the pipes. These heaters had excess heat capacity and, during operation, control system failures were experienced where the controllers for piping heaters failed full on and caused thermal transients. If the transfer piping heaters are sized at between 18 and 42 watts per linear foot, it has been found that there should be no concern with runaway heaters. Theoretically, a heater control system would not be needed. Eighteen watts of trace heat, with two inches of insulation, will be able to heat the transfer lines to $204{ }^{\circ} \mathrm{C}$ $\left(400^{\circ} \mathrm{F}\right)$ very slowly and reach an equilibrium condition where the outside insulation temperature does not exceed $60^{\circ} \mathrm{C}\left(140^{\circ} \mathrm{F}\right)$.

Flexible metalclad mineral insulated cable ultimately appears to be the best available method for heating the sodium transfer lines. MI cable has the following advantages:

1) It can be easily routed over pipe hangers and around bends without any special forming procedures

2) The Mi cable is designed to be either cemented or clamped directly to the piping.

3) It can be run in longer lengths than Cal Rod heaters, which requires fewer electrical connection points.

4) It costs less per linear foot than an equivalent number of CAI Rod heaters.

Because the trace heat will be applied directly to the piping instead of in an oven arrangement, which is what was done with FFTF piping, the amount of applied heat can be reduced which reduces the overall cost of this project.

During the initial sodium fill of the FFTF plant, a flexible heater cable was used on parts of the sodium fill line (See drawing H-4-53346, Sheet 2. Revision 1). This type of cable is no longer commercially available, but this is not a problem. The Inconel Clad Mineral Insulated (MI) trace heat cables that are available for use today are better quality equipment than that which was available during initial FFTF sodium fill.

HNF-SD-FF-SDD-002 Rev, 0

Page 5 
On the piping a redundant string of 18 wat $/ \mathrm{ft}$ heater cables was installed connected in parallel. This method accelerated the heat up rate for a melt out, or the control system would automatically compensate for a failed heater string.

\subsection{SYSTEM DESIGN BASES}

\subsubsection{Authorization basis}

The SSF and all of its systems were exempted from the Unresolved Safety Question process and the entire facility is exempt from the requirements to create an authorization basis process. This PRC meeting was held on August 12, 1996. See A-39 for further details.

\subsubsection{Design inputs}

Since this equipment was purchased under a construction contract, this equipment was built to the 1993 National Electrical Code because that was the code in effect when the contract was let. This is the reason that ground fault breakers are installed on the B-3001, B-3012, and B-3013 main breakers instead of on the feeder breakers as is now required by article 427 of the 1996 code.

Other design considerations are listed in SSF contract sections 16856, 16857, 16903, 16904, and 16950 and submittals $110 . \mathrm{A}, 111,114$, and $216 . \mathrm{A}$ of the project files.

\subsubsection{Design constraints}

The only system design constraints were those temperature requirements that have already been discussed in sections 3.2 .3 and 3.2 .7 above.

\subsubsection{Special material or system chemistry considerations}

Dealing with molten sodium is a unique experience. As mentioned previously, pure sodium has a melting point of $208{ }^{\circ} \mathrm{F}$. The FFTF sodium, while it is not pure, has been closely monitored for impurities and melts at about 208 to $220^{\circ} \mathrm{F}$ as measured on a near isothermal section of pipe. The sodium that will be stored in SSF contains trace amounts of $\mathrm{NaK}$, cesium, tritium, and other impurities

Sodium does not create aerosols until it is heated to over $450^{\circ} \mathrm{F}$. If a cover gas pressure surge should rupture the disc and lift a relief and if temperatures are greater than $450^{\circ} \mathrm{F}$, aerosol deposition could prevent the relief valve from resetting. But the possibility of this happening is the reason that normal operating temperature should be set low at about $325^{\circ} \mathrm{F}$ if possible.

Some impurities in the sodium effect what is commonly called plugging temperature. This name comes from the way that this property is measured. Basically this property is a measure of the gross impurity level in the sodium and affects where impuritics will plate out in the system. It is advisable to keep the temperatures at valves and other moving parts above previously measured values of sodium plugging temperaturc (typically grcatcr than $260^{\circ} \mathrm{F}$ ).

\subsubsection{Design analysis and calculations}

During the preliminary design phases of operation it was determined that only 18 to 22 watts per linear foot were required to melt out a 2" pipe that contained frozen sodium. As built, there is an average of about 28 watts per linear foot. The exact wattage values are shown on drawing H-4-302529, Sheet 9 . 


\subsection{COMPONENT REQUIREMENTS AND BASIS}

\subsubsection{Major components descriptions}

A. Thermocouple Description

Ideally, the thermocouple should read the actual pipe temperature rather than the heater cladding temperature so several methods of thermocouple attachment were evaluated. The thermocouple sensors that were used are a metalclad, mineral insulated, ungrounded type $\mathrm{K}$ thermocouples very similar to what are used in the FFTF. The sensors on the tanks were cemented directly onto the tank using OMEGABOND 300 and a wire mesh was used as a backup attachment. The mesh was clamped to existing Nelson studs on the outside of the tanks. The piping TEs were attached using stainless steel banding material. This should eliminate the problem of sensors lifting off of the pipe thermocouple problems that has occurred in the past.

The project design also addressed concerns about induced electromagnetic interference (EMI) from the heater cables. By using shielded ungrounded thermocouples, any noise induced onto the shield is drained at the control panels. In order to ensure that this system is effective, the shield (or guard) was tested and inspected for continuity from the thermocouple cladding all the way to the monitoring system. The shield is grounded (drained) only at PLC $\mathrm{I} / \mathrm{O}$ card inside the temperature monitoring panel C-3005.

See drawing H-4-302529, Sheet 12 for additional details.

B. Heater Description

The majority of the heaters in the facility are flexible, metalclad, mineral insulated cable. On the sodium valve bodies, bonnets, and short sections of piping, a band type heater will be used. Unlike the heaters in the FFTF plant, both of these heaters rely on conduction heat transfer mode of operation. The heaters will be clamped and/or cemented directly onto the pipe and tank walls (see drawing H-4-302529, Sheets $1-12$ for additional information).

C. Supervisory Control and Data Acquisition (SCADA)

SCADA is the completely integrated control system. It consists of the computer, PLC, and power controllers. Drawing H-4-302501 is a Block Diagram of the control system

Drawing H-4-302502 is a typical instrument diagram showing how the control system averages the thermocouple inputs to control heater power.

Drawing H-4-302504, Sheet 1 of 2 , is a one line diagram of the trace heat control system power distribution system.

Drawings H-4-302505, H-4-302506, and H-4-302507, Sheets 2 of 3, show how the power controlling SCRs are connected to the control system and the heater power distribution system.

Drawing H-4-302529, Sheets 10-11, are the typical wiring diagrams for the different configurations of trace heat control zones.

The vendor provided System Design Description provides additional details on how the software files fit together to monitor and control the system.

HNF-SD-FF-SDD-002 Rev. 0

Page 7 
D. Programmable Logic Controller (PLC)

The PLC is an Allen Bradley model SLC-5/04 which is capable of handling up to 960 input or output devices. The PLC in this control system is not dependent upon the computer to operate the control system. The control algorithms are downloaded from the computer into the PLC's memory. The system can operate for a year or more without any operator input. For this reason, a failure of the computer will not result in a loss of control, only a loss of monitoring data. Security protocols will be in effect when the system is running to prevent access to the control database and a warning window will be displayed if the operator tries to close the application that is responsible for data acquisition.

The PLC consists of 2 CPU units, 1 digital input module ( 8 channels) for the tank pressure switch inputs, 3 output modules ( 32 channels each) and 43 TE input modules ( 4 channels each)

The input goes through the input modules to the CPU modules, the temperatures for each zone are averaged (or out of range TEs are dropped out of the zone average), the CPU compares the average temperature to the setpoint and computes an output signal (temperature rate limited to 50 degrees per hour) and sends the signal to the output module which sends the signal to the power controller

If the computer died, the setpoint that was last input would remain in the CPU, the CPU would continue to scan, and average the temperatures and calculate output so the control system would heatup to the setpoint and maintain that temperature. If the system was in manual control, the heater output that was called for would continue to be called for regardless of system temperature if the computer was lost.

Security protocols will be in effect when the system is running to prevent access to the control database, and a warning window will be displayed if the operator tries to close the application that is responsible for data acquisition.

E. Power Controllers

There will be basically two models of the same SCR based controller. One version will be a single phase proportional type of controller for the valve and piping heaters, and the second type will be a three phase on/off type of controller. Both types are zero crossover firing controllers, to minimize the generation of electrical noise in other circuitry, just like the Halmar Power controllers that are installed in the JCMs in the FFTF plant (see the attached Watlow "DIN-A MITETM" vendor information shects for more information).

The controllers are rated for a 3-32 vdc input signal. One type of single phase controller output is rated for 120 to $240 \mathrm{vac} 16$ amps, the other type of single phase controller is rated for 120 to $240 \mathrm{vac}$ and 30 amps. The three phase controllers are rated for 277 to $600 \mathrm{vac}$ and 50 amps. These are provided with 120 vac fans for cooling.

\subsubsection{Required functions}

This system is only a monitoring and control system.

\subsubsection{Design basis}

This document is the design basis document for this system.

$$
\text { HNF-SD-FF-SDD-002 Rev. } 0
$$

Page 8 


\subsubsection{Component function}

Included in section 3.4 .1 above

\subsubsection{Design basis satisfaction}

N/A

\subsubsection{Designer option}

N/A

\subsection{DESIGN DESCRIPTION}

\subsection{DETAILED SYSTEM DESCRIPTION}

\subsubsection{Block Diagrams}

Drawing H-4-302501, Sheet 1 , is a good representation of how the parts of the control system connect together. The system parameters are sensed by thermocouple and the four pressure switches. The pressure switches are either an open or closed dry (de-energized) contact so they must be sensed by the PLC by the Allen Bradley model 1746-IA8 digital input module. The thermocouple inputs are connected to the Allen Bradley model 1746-NT4 thermocouple/mv Analog Input module. This module provides Cold Junction Compensation, multiplexing, Analog to Digital conversion, and Digital Signal Filtering functions. This module then passes the corresponding value to the PLC's Driver Image Table

Output from the PLC is fed to the input terminals of the Watlow SCRs from the three Allen Bradley model 1746-OB32 Digital Output modules. This output signal is a digital signal that controls the pulse width of the SCR module's output. The Watlow SCR modules are Zero Cross Over firing, and pulse width modulation as describe in the vendor information files does describe a time based output that allows the SCRs to conduct for a certain number of cycles during a fixed period of time, just like the Halmar JCs in the FFTF trace heat system.

\subsubsection{Simplified Schematic Diagrams}

Drawing H-4-302502 shows a simplified schematic that uses symbols similar to the instrument diagrams that have been used at the FFTF for years. This drawing shows the functions that the computer performs as if these functions were performed by discrete hardware modules. Two, Three, or Four thermocouple signals are sensed by the PLC input modules and checked to see if they are valid. There are High and Low temperature alarms for individual Tes. And then the TE signals are averaged. The Abbreviation of PID on the drawings stands for Proportional, Integral, and Derivative. When the control system is in Automatic Mode, a rung on the PLC ladder logic diagrams performs heal-up rate control in the same manner as if we had a discrete Temperature Indicating Controller operating the system instead of a computer.

Drawings H-4-302505, -302506 , and -302507 , sheets 2 of 3 , were provided as examples of the Digital input, power input, and power output leads are connected the respective Watlow SCR modules. 
Drawings H-4-302505, 302506, and 302507, sheets 3 of 3 , show how the output from the PLC Digital Output module are connected via the Allen Bradley IFM40F interface modules to the terminal strips, then are subsequently connected to the WATLOW SCR modules.

Drawing H-4-302509, sheet 2 of 4, shows how the input and output wiring is connected to the PLC. Of particular interest is the digital output drawing that shows how the Allen Bradley IFM40F interface module is connected.

Drawing H-4-302509, sheet 3 of 4, shows how the inputs are connected to the PLC, however this drawing is not as clear as could be. The three digit alpha-numeric code like ID0 is broken out as follows: the " 1 " stands for rack $\# 1$. The " $D$ " stands for a module or slot position. The " 0 " is a terminal number on the module. The drawing on the next page shows a redo of H-4-302509, sheet 1 , that puts the rack and slot positions into perspective. 


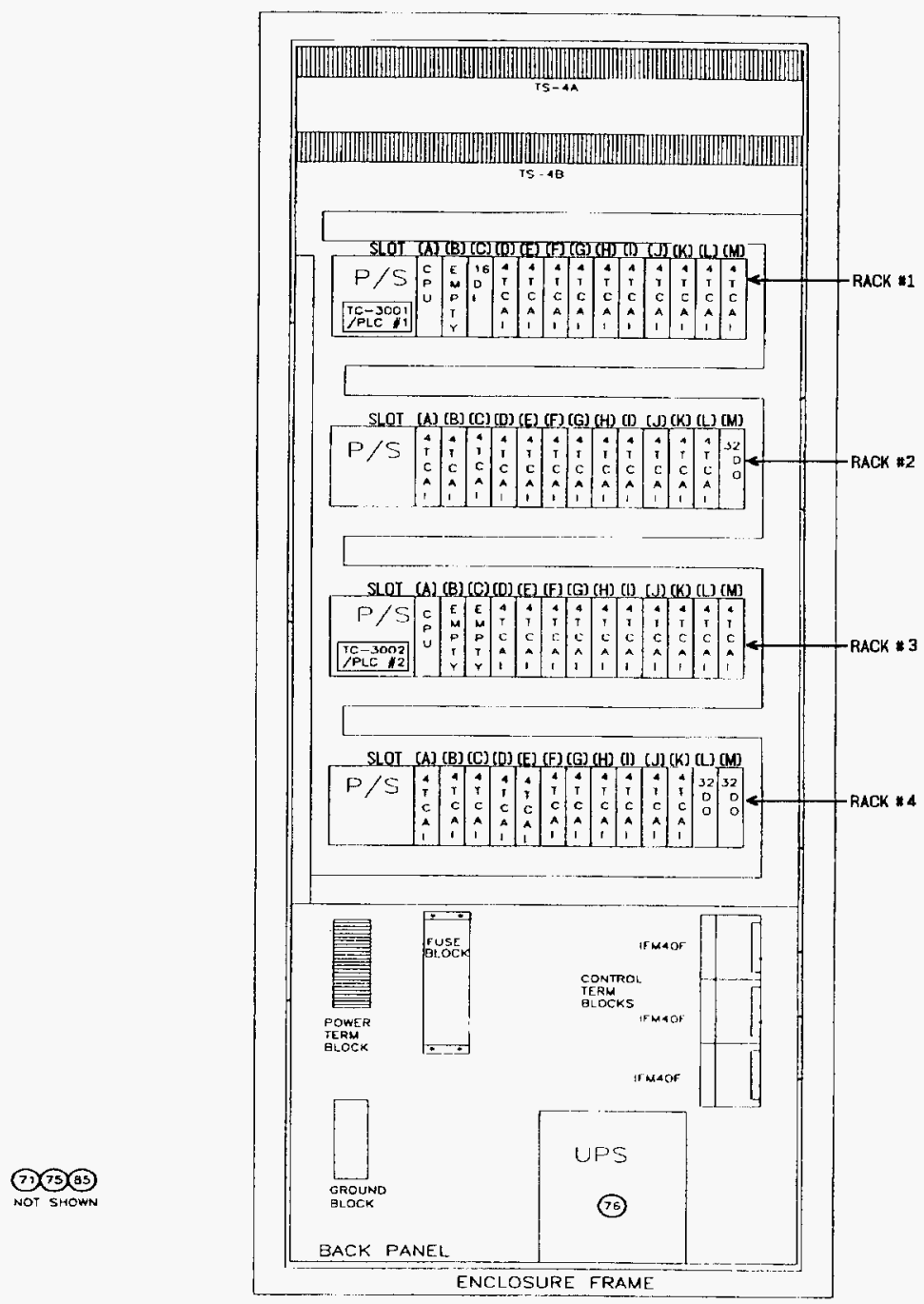

FRONT VIEW

PLC Module Positions 
In automatic mode, the temperature control system is capable of controlling the heat-up rate at less than or equal to $20^{\circ} \mathrm{F} / \mathrm{hr}$ for the Storage Tank control zones. For the piping and valve zones, the system is capable of controlling heat-up rate to keep it less than or equal to $50^{\circ} \mathrm{F} / \mathrm{hr}$.

\subsection{SYSTEM ARRANGEMENT}

Drawing H-4-302444 provides an overview of the piping trace heat zones. Drawing H-4-302529, sheets $1-8$, provide details of trace heater layout.

Drawing H-4-302503 shows how all five sections of the trace heat control panels are laid out in room 104. Sheet $\mathrm{l}$ of drawings H-4-302505, H-4-302506, H-4-302507, H-4-302508, and H-4-302509 shows how the component parts are laid out with in the control panels.

\subsection{COMPONENT DESIGN DESCRIPTIONS}

As mentioned in section 3.2.10, the electric heater cables are Stainless Steel (SS) clad Magnesium Oxide insulated resistance type heaters. These heaters were manufactured by Accutron Systems, Inc., of Hyde Park, Ontario, Canada. The cable sheath is a high nickel alloy, SS Alloy 825. Installation instructions were provided on sheet 12 of H-4-302529 and as part of Vendor Information file \#22710 referenced in Appendix F

Additional heat is provided to valves and small sections of piping by Mica Insulated band heaters manufactured by Fast Heat, Inc., of Elmhurst, IL. These heaters are rated to 900 degrees $\mathrm{F}$.

The thermocouple elements are SS clad ungrounded type K thermocouples (see drawing H-4-302509, sheet 4 of 4 , and H-4-302501, sheet 2 of 2 , for vendor part numbers).

The model of Allen-Bradley PLC that is used for this project is the SLC $500^{\mathrm{TM}}$ CPU with 20 Kbytes of installed memory. This system uses the Data Highway Plus option to communicate with the PC. When studying about this equipment in the Installation and Maintenance Manual, ignore Appendixes $A, B$, and $C$ about other types of communication networks because they do not apply to our installed hardware.

The PLC chassis style that is used is the Allen-Bradley model 1746-A13 13 slot chassis. The power supply module is the 1746-P2. The thermocouple inputs are connected to the PLC via the model 1746-NT4 modules. The rupture disc PSHs are connected to the PLC via the model 1746-IA8 AC input module. Output to the SCR modules is via the model 1746-OB32 DC output modules. Reference to other part numbers is provided on drawing H-4-302501, sheet 2 of 2 .

The control system uses four models of Watlow SCRs to control power to the heaters. These models are:

1) DC3C-3060-C000 Three phase, contactor type output control, $30 \mathrm{amp}, 277$ to $600 \mathrm{VAC}$ output, 5 to 50 VDC inputtype, with out short circuit alarm and no cooling fan.

2) DC3C-5060-C001 Three phase, contactor type output control, $50 \mathrm{amp}, 277$ to $600 \mathrm{VAC}$ output, 5 to $50 \mathrm{VDC}$ input type, with out short circuit alarm and does have an installed cooling fan. 
3) DA 1C-1624-C000 Single phase, contactor type output control, 16 amp, 120 to 240 VAC output, 5 to 50 VDC input type, with out short circuit alarm and no cooling fan.

4) DBIC-3024-C000 Single phase, contactor type output control, $30 \mathrm{amp}, 120$ to $240 \mathrm{VAC}$ output, 5 to 50 VDC input type, with out short circuit alarm and no cooling fan.

The ground fault protection relays are made by Westinghouse Electric Corp., catalog number GFR60ED, Style 1293C83G02. This is a 120 Volt DC control relay which is electrically reset without zone interlocking. The current and time settings are adjustable with switches mounted on the front of the relay. The relay setpoints are listed later in section 4.7.4. These relays require 120 VAC and 125 milliamps from B-3011 breaker 3 for the sensing coil operation. These units also require $125 \mathrm{VDC}$ at 125 milliamps for control power. $\mathrm{AC}$ to DC power supplies are mounted in the breaker panels with the relays and coils.

Test and reset panels for the relays were not installed as part of the vendor installation and should be installed before facility operation. See FFTF work package 4S-96-0022/M or the vendor information file for more information on this equipment.

\subsection{INSTRUMENTATION AND CONTROL}

This system is an instrumentation and control system. All of the information contained in this document describes this instrumentation.

\subsection{SYSTEM INTERFACES}

Sufficient detail on the system interfaces is provided in sections 2.2 and 2.3 .

\subsection{SYSTEM LIMITATIONS, SET POINTS, AND PRECAUTIONS}

\subsubsection{Trace Heat Alarms}

A. Variable trip setpoints dependent on the last operator input. These limits are set by the operating conditions and procedures for the facility.

\subsubsection{PSH Alarms}

A. Trips at 8 psig sensed between the rupture disc and relief valve.

\subsubsection{Hardware}

A. Loss of communication between the PLC and the PC activates a software Watchdog Timer which activates the alarm when it times out.

\subsubsection{Ground Fault}
A. B-3001 instantaneous current to ground of 60 amps.
B. B-30/2 instantaneous current to ground of 20 amps.
C. B-3013 instantancous current to ground of 45 amps. 


\subsubsection{Symptoms}

A. Alarms displayed on monitor and/or printed out on the line printer.

B. Uncontrolled cooldown/heatup of components.

C. Loss of power to the heated components.

D. Pressure greater than $8 \mathrm{psig}$ in the SSF sodium storage $\operatorname{tank}(\mathrm{s})$.

E. Main breaker in B-3001, B-3012, or B-3013 in the tripped free position.

F. Individual breakers tripped for the effected zone.

\subsection{OPERATIONS AND CASUALTY EVENTS}

\subsection{OPERATION}

As mentioned previously, this system will be used to sequentially melt out/heat up the SSF sodium piping and storage tanks. The sequential nature of the procedure was chosen based on the contingency that the instructions can be used even if the FFTF to SSF drain evolution has to be stopped before the drain is complete. These instructions are included in SN-93.15-2.

When the trace heat is used to preheat the transfer piping to $149^{\circ} \mathrm{C}$ to $177^{\circ} \mathrm{C}\left(300^{\circ} \mathrm{F}\right.$ to $\left.350^{\circ} \mathrm{F}\right)$, the piping will be exposed to only a minimal amount of thermal shock when the sodium transfer begins. The trace heat will also keep the sodium in the piping molten during transfer. If something stops the transfer before it is complete, the MI cable needs to be able to apply at least 18 watts per linear foot to transfer piping in order to have enough capacity to melt the sodium trapped in the pipe.

\subsection{CASUALTY EVENTS AND RECOVERY PROCEDURES}

\subsubsection{Casualty events}

This equipment fails safe in the off condition for a loss of all electrical power casualty. This equipment is not safety, environment, or a quality affecting. For this reason, seismic, tornado, fire, or flooding casualties do not need to be evaluated for this equipment.

\subsubsection{Design features to mitigate effects of casualty events}

Should the sodium drain need to be secured for any reason, it is anticipated that siphon will be broken and residual sodium in the lines will drain back to T-44. As mentioned in the System Description, operators will be able the change individual setpoints so that a sequential melt-out will be possible starting at either T-44 or one of the storage tanks.

\subsubsection{Recovery procedures}

Recovery procedures are provided in SA-93.15-2. 
6.0 MAINTENANCE, INSPECTION, AND SURVEILLANCE

\subsection{MAINTENANCE}

At this time no preventive maintenance is anticipated or desired to be performed. The FFTF is currently back in a standby status awaiting the decision to restart for tritium and medical isotope production missions or to proceed with deactivation activities. If sodium drain commences before January of 1999 , then no preventive or corrective actions are necessary. Further actions regarding long term software preservation will be addressed in the Software Configuration Control Plan HNF-SD-FF-CSCM-009.

\subsection{INSPECTION}

Periodic cleanliness inspections of 402/104 need to made on an annual basis.

\subsection{SURVEILLANCE}

None.

\subsection{TESTING}

The system acceptance test procedure is recorded as a supporting document entitled Heat Trace Systems Acceptance Tests, 400 Area Building 402, Project F-031, WHC-SD-F031-ATP-004.

8.0 OPTIONAL INFORMATION

None.

8.1 DESIGN MARGIN

None.

\subsection{SUMMARY OF CRITICAL CALCULATIONS}

None.

\subsection{POSTULATED FAILURES}

Loss of programmed information due to Hard Disk Crash, or Dersolution from non-use

\subsection{RESPONSE TO TRANSIENTS}

None.

\subsection{TESTING AND TESTABILITY REQUIREMENTS}

None

\subsection{RELIABILITY ASSURANCE}

None. 
9.0 REFERENCES/BIBLIOGRAPHY

9.1 Intellution $(\mathbb{R})$ software manuals for version 5.5 - $(1988-1995$, Intellution( $(\mathbb{R})$ Inc., All Rights Reserved: manuals included in the set are:
a. Display Development
b. System Setup
c. Advanced Tools
d. System Development
e. Allen-Bradley KT/KT2 (ABK) I/O Driver Manual
f. Message Handler Manual
g. Dynamos
h. Upgrade Guide

9.2 Rockwell Software inc. Manuals

a. Advanced Programming Software Version 6.0 User Manual - Document ID 9399-APSUM11.15.95, copyright $\bigcirc 1995$, no author credited.

b. Advanced Programming Software Version 6.0 Import/Export Utility User Manual Document ID 9399-APSIE-11.15.95, copyright (01995, no author credited.

9.3 Allen-Bradely SLC 500 $\mathrm{TM}$ Instruction Set Reference Manual, author not credited, published January 1996 Part Number 956500-01 Publication \# 1747-6.15 


\section{APPENDIX A}

\section{DRAWING LIST}

1) H-4-302444 sheet 1 shows an overview of the piping trace heat zones. For detail heater application drawings, see drawing H-4-302529, sheets 1-9.

2) H-4-302445 has been superseded by H-4-302529, sheets 7 and 8 , but used to show a simplified layout of the Storage Tank trace heat zones.

3) H-4-30245I, sheet I of 2, shows the electrical supply to the SSF Trace Heat Control System.

4) H-4-302451, Sheet 2 of 2, shows the Trace Heat Panel board load list for isolation of the individual control zones

5) H-4-302452, sheets 1-3, presents an overview of the control system.

6) H-4-30250 I, sheet I of 2 , is a block diagram of the control system.

7) H-4-302501, sheet 2 of 2 , is the trace heat control panel parts list.

8) H-4-302502 is an instrument diagram that represents an equivalency of how the computer control system would work if it were implemented with discrete hardware controls.

9) H-4-302503 shows how all five sections of the trace heat control panels are laid out in room 104

10) Sheet 1 of drawings H-4-302505, H-4-302506, H-4-302507, H-4-302508, and H-4-302509 shows how component parts are laid out within the control panels.

11) Sheet 2 of drawings $\mathrm{H}-4-302505, \mathrm{H}-4-302506$ and $\mathrm{H}-4-302507$ provides a schematic of how the SCRs are interconnected with the power and control system.

12) Sheet 3 of drawings H-4-302505, H-4-302506, H-4-302507, and H-4-302509 provides the interconnection diagrams for the interface between the field wiring or the SCRs and the PLC.

13) H-4-302509, sheet 2 , shows PLC input wiring interfaces. Sheet 4 gives thermocouple details.

14) H-4-302529, sheets $1-6$, shows detailed application of trace heaters to the sodium valves and piping.

15) H-4-302529, sheets 7 and 8, provides details on the storage tank heaters.

16) H-4-302529, sheet 9, provides calculated heater current and power values. Actual values measured in the field should be obtained from WHC-SD-ATP-004.

16) H-4-302529, sheets 10 and 11 , provides representations of typical zone wiring diagrams.

17) H-4-302529, sheet 12 , provides Accutron Trace Cable installation details. 
APPENDIX B

SUPPORTING DOCUMENTS

1) HNF-SD-FF-SDD-002, SODIUM STORAGE FACILITY TRACE HEAT CONTROL SYSTEM DESIGN DESCRIPTION

2) HNF-SD-FF-CSCM-009, SSF SOFTWARE CONFIGURATION CONTROL PLAN

3) HNF-SD-FF-CSWD-060, SSF TRACE HEAT CROSS REFERENCE

4) HNF-SD-FF-CSWD-061, SSF LADDER LOGIC DIAGRAMS

HNF-SD-FF-SDD-002 Rev. 0

Page 18 


\section{OPERATING PROCEDURES}

The procedures for this system are maintained by the FFTF Operations Analysis \& Support organization. These systems are all referred to as FFTF Startup system S93B in the FFTF JCS system. The existing procedures areas follows:

1) SN-93.15-2, OPERATION OF THE SSF TRACE HEAT SYSTEM

2) SA-93.15-2, RESPONSE TO SSF TRACE HEAT ALARMS AND RUPTURE DISC HIGH PRESSURE ALARMS 
APPENDIX D

MAINTENANCE PROCEDURES

There are currently no active Maintenance Procedures for this system.

APPENDIX E

SURVEILLANCE AND INSPECTION PROCEDURES

There are currently no SISI or PMP procedures for this system.

\section{APPENDIX F}

\section{VENDOR INFORMATION FILES}

The Vendor Information file that contains the majority of the vendor provided information on the system hardware and software that was used is stored under index number: 22710, Supp. 10.

The Equipment Title is Sodium Storage Temperature Control System \& Electric Heater Power Control Cabinet.

The Vendor/Manufacturer Name on the VI file is: Equipment Technology \& Design.

The Project No./Work Order number is: $\mathrm{F}-031 / \mathrm{C} 2 / 109,115, \& 120$.

APPENDIX G

\section{PARAMETERS LIST}

Nol Used

APPENDIX H

INSTRUMENT LIST

Not Used

\section{APPENDIX I}

\section{VALVE LIST}

No Valves are contained within the boundaries of this system. 
APPENDIX J

EQUIPMENT LIST

The equipment list is contained in the FFTF JCS component index.

\section{APPENDIX K}

\section{TRAINING LIST}

An operations training manual has been prepared for this equipment. Since these documents were prepared at about the same time, and using a graded approach, some of the information in these two documents is a duplication. 


\section{APPENDIX L}

\section{COMPUTER HARDWARE AND SOFTWARE LIST}

\subsection{INTRODUCTION}

\subsection{Purpose}

The SCADA System for the SSF has been configured to provide monitoring of the heat tracing system's temperature through thermocouple signals connected to the PLC I/O modules. The monitoring system provides an overview screen with a graphical (real world/mimic) view of the various physical components of the SSF. Additional screens display individual, or average zone temperature, and alarm conditions. The information received by the SCADA system is stored for later use to provide Historical Display charts for analysis of the system.

\section{$1.2 \quad$ Scope}

This system was designed to monitor the temperature of the electrically heated section of sodium piping in the SSF. It also monitors the $4 \mathrm{PSH}$ on the relief lines. This provides control functions only for the electric heaters. It does not control electrical distribution, lighting, HVAC, tank pressure, sodium flow, or any of the other equipment in the SSF. This system at some time in the future could be connected to a Local Area Network but that is not now needed or desired.

\subsection{Overview}

Basically the Allen Bradley PLC is controlled by its own Ladder Logic Program. This Ladder Logic was created using the Rockwell Advanced Programming Software (APSTM) Release 6.0. This software contains an Application Programming Interface (API) called "INTERCHANGE." INTERCHANGE allows APSTM software to use the Allen-Bradley KTX Data Plus highway card installed in the computer to communicate with the PLC. This communication link is a serial link that operates at a baud rate of approximately $50 \mathrm{~K}$ baud

The Intellution $(\mathbb{E})$ software provides the graphical operator view screens. This software is a completely visual or object oriented software package. This package includes a DATABASE BUILDER Program, a Drawing program, and Historical Trending applications. The Intellution(B) software and the APSTM software share a common memory array called a Driver Image Table. This Driver Image Table was originally created as Microsoft (MS) EXCEL spread sheets. These files were compiled with MS EXCEL macro routines. Then the Intcllution( DATABASE BUILDER application is opened and communication with the Supervisory Control And Data Acquisition (SCADA) node is established, and then the spreadsheets is opened to display blocks from SCADA nodes active database. Objects in the shared memory locations arc identified by unique Tag Names. The Tag Name ties the Object on the drawing, to the Data Base, and to the PLC Ladder Rung.

The tag name for an Object can be edited in Draw from the Data Link Dialog Box, or from the Data Base Builder. When there was a problem with two Thermocouple indications being swapped, it was much easier to make sure that you were correcting the right item if the Data Link Dialog Box was used to perform the edit. 
Assembly Language: A symbolic language provided by the manufacturer of a microprocessor to perform the most basic processor functions. This code is then compiled into Machine Language that is not normally readable by humans.

CV: Control Variable; Output from the controller to the process controlling device.

Data Base: A data file arranged in a mathematical matrix form. These software applications can contain text, numerical data, and many other types of objects. For the purposes of this application the database contains mainly text and numerical data.

$\underline{\mathrm{DH}}+$ : Data Highway Plus; A proprictary form of serial communications network used by the AllenBradley hardware.

MMI: Man Machine Interface; The logical process of converting raw data from instruments in the field into text and pictorial information that can easily be understood by the operator.

Qbject: A tool, item, icon, or location placed on a drawing or form that can be connected to data or program subroutine. This form of computer programming seems to be more "User Friendly" to equipment operators and other people than text based sequential programs. For this reason, this type of application was chosen for our use. For example, an operator can click on buttons on the overview screen and choose other screens to look at. The button is a tool that causes the overview window to be hidden and the next picture to be loaded. Another example is when a valve or label football tums Red in response to an alarm. This object is tied to a digital alarm channel by the devices Tag Name.

PC: Personal Computer; a microprocessor based computer or microcomputer.

PID: Proportional, Integral, and Derivative control; This type of system is a dynamic control system, that uses a combination of all three types mathematical features to adjust $\mathrm{CV}$.

PLC: Progranmable Logic Controller; A microprocessor based control system that replaces older relay logic types of control systems. The electronics industry as a whole has been shifting towards these types of systcms because they are typically smaller, easier to maintain and change than discrete component systems that are hard wired.

PSH: Pressure Switch High; A sensor that closes a switch contact when the system pressure exceeds a calibrated setpoint.

PV: Process Variable; The input recieved from sensors on the process.

SCADA: Supervisory Control and Data Acquisition; A bundled system that scans input devices, records data, and controls system parameters based on the data it receives.

SSF: Sodium Storage Facility; Building 402 in the 400 Area of the Department of Energy's Hanford Site. This Facility will be used as a location to store the sodium that is to be removed from the Main Heat Transport Systems of the Fast Flux Test Facility when this facility is decommissioned. 
Spreadsheet: An automated version of an accountant's workbook that is used for storing and manipulating data stored in matrix form. These application software packages are very similar to database softwarc. For this reason, a spreadsheet can be used for many purposes. In the case of the Intellution ${ }^{\mathrm{TM}}$ sotware package, the Excel ${ }^{\mathrm{TM}}$ spreadsheets were used to sequentially create the much larger device control and data recording database.

Tag Name: A shorthand notation developed, in our case by Allen-Bradley, for shared memory locations that both the PC and the PLC to use to tie information together.

HDW: Hardware Alarm; Open or themocouple out of range.

TE or T/C: Thermocouple; Temperature sensing device.

\section{$1.5 \quad$ Materials}

A) A copy of MS DOS Version 6.22 (3 disks)

B) A copy of MS Windows for Workgroups Version 3.11 (8 disks)

C) The 12 standard Intellution $(\mathbb{R})$ Version 5.5 Disks

D) Intellution I/O Driver Disk for Windows Version 5.5

1.6 Input

The process input comes directly into the PLC $1 / O$ modules. The $1 / O$ modules convert the thermocouple millivolt signals into digital data that is stored in the PLC's memory registers. The PSH alarm switches only require one bit data storage since they are either on or off.

Control and alarm setpoints are input by the operator via the key board and mouse. The Intellution ${ }^{\mathrm{TM}}$ database module stores these changes the the database files; path:

\section{C:IWDMACS\PDBISODIUM.PDB}

When the PLC is ready then these new setpoints are down loaded to the PLC. This is apparent as deadtime (Windows hourglass displayed where the mouse pointer normally is) on the heater setpoint screens. More information on how this transfer occurs will be presented in the next section.

\subsection{Preliminary Design Phase}

The program developers could have started in one of three ways. They could have created the drawing files, or PLC ladder logic, or the Excel ${ }^{\mathrm{TM}}$ spreadsheets. Because the basic layout of heaters and thermocouples was provided in the project contract drawings, the programmers probably started by devcloping the spreadsheets needed to build the control data base for the MMI. The key field in this database is a unique Tag Name for each input, output, and alarm type. Another very important field in this database is the I/O Address field. The address in this field must be compatible with the addressing structure provided in the SLC500 ${ }^{\mathrm{TM}}$ Instruction Set Manual pages 1-3 through 1-8. An example of this format is provided here for information only: TE-110Al has a PLC I/O address of DEV1:N7:1. 
"DEV" stands for device; "l" is the first PLC CPU (our system uses two SLC 5/04 CPU's); N7 designates that this is and integer file; the colon is an Element Delimiter; and the number " 1 " is the Element Number. Element numbers range from 0 to 255. If the TE-110A1 T/C Out of Range alarm address was used as an example, its I/O address has a slightly different address: DEV $1: N 7: 148 / 0$. In this case, this address also has a Bit Delimiter " $"$ " and a Bit Number " 0 ". Since alarm or control flags have only either an on or off state, then there is room for sixteen single bit flags in a register.

Thus

DEV1:N7:148/1

DEVI:N7:148/2

DEV1:N7:148/3

DEV 1:N7:148/4

DEVI:N7:148/5

DEVI:N7:148/6

DEVI:N7:148/7

DEV I:N7:148/8

DEV I:N7:148/9

DEV1:N7:148/10

DEV $1: N 7: 148 / 11$

DEVI:N7:148/12

DEVI:N7:148/13

DEVI:N7:148/14

DEVI:N7:148/15

\begin{abstract}
for TE-110A2 T/C Out of Range, for TE-110A3 T/C Out of Range, for TE-110A4 T/C Out of Range, for TE-110B1 T/C Out of Range, for TE-110B2 T/C Out of Range, for TE-110B3 T/C Out of Range, for TE-110B4 T/C Out of Range, for TE-110Cl T/C Out of Range, for TE-110C2 T/C Out of Range, for $\mathrm{TE}-110 \mathrm{C} 3 \mathrm{~T} / \mathrm{C}$ Out of Range, for TE-110C4 T/C Out of Range, for TE-I11AI T/C Out of Range, for TE-111A2 T/C Out of Rangc, for TE-11LA3 T/C Out of Rangc, for TE-111A4 T/C Out of Range,
\end{abstract}

are all valid register addresses. These addresses are all listed in the tables of supporting document HNF-SD-FF-CWSD-60, Rev. 0, "SSF Trace Heal Cross Reference."

The next step in the process was to create the PLC ladder logic. To create the ladder logic, a progranmer has to install the Rockwell APSTM Interchange ${ }^{\mathrm{TM}}$ software. The creation of the ladder logic for this PLC is similar to other PLCs of various manufacturers. To get a basic grasp of what is contained in the PLC ladder logic files, study appendix H of the SLC500TM Instruction Set Manual. A detailed study of the SSF ladder logic requires the programmer to study HNF-SD-FF-CSWD-61 with the SLC500 ${ }^{\mathrm{TM}}$ Instruction Set Manual and the Rockwell APS ${ }^{\mathrm{TM}}$ Release 6.0 User Manual. The Rockwell APS TM Release 6.0 User Manual explains how to install, configure, and use the Interchange ${ }^{\mathrm{M} M}$ software to write a ladder logic program. The SLC500'M Instruction Set Manual explains the assembly language of the processor in the in the Allen-Bradlcy PLC.

The final step is to create the MMI. The MMI is purely graphical. It is Object Oriented. This means that the the developer draws a picture of the sodium process piping, which contains objects that represents the TEs and PSHs in the system. When one of these objects goes into alarm its icon on the overview screen goes from green to red as described in section 5.2. The reason that this happens is because each object is connected to a memory address by its Tag Name. The Tag Name is a unique to each type of object. The different types of objects that are used for this system are:

Analog lnputs: These blocks retrieve analog average temperature for a control zone from the PLC Driver Image Table, and compares this data to the high and low limits set by the programmer for determining an Out of Range (OOR) alarm.

Analog Alarms: These blocks retrieve individual TE values from the PLC Driver Image Table, and compares this data to the high and low limits set by the operator. 
Analog Outputs: These Blocks provide a register location for the storage of the control setpoint that is input by the operator.

Digital Inputs: These blocks seem to be used to provide several functions. One function is to provide simulated devices that are used to show an alarm condition on the overview screen when any of the individual devices associated with that object have gone into alarm. Another function is to provide a register location to tell the PLC when the operator has selected either manual or automatic operation.

Digital Outputs: These blocks also seem to be used for several functions. One function is to provide a register location to tell the PLC when the operator has turned the PID control option on. Another function is used to manually force a TE to be rejected from the zone average.

Digital Alarms: When the OOR condition is detected by the analog input block, the corresponding Digital alarm channel state is changed from " 0 " to " 1. "

For more information on the software block types see the Intellution ${ }^{\mathrm{TM}}$ Database Reference manual pages 7 through 14 and 33 through 38 .

\subsection{Logical Process Model}

The logicial process model shown here presents how the hardware in this system is related.

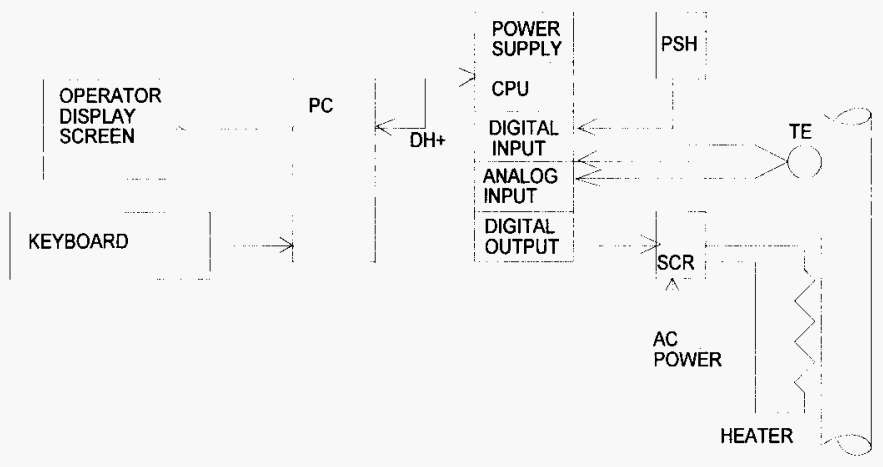

From the PC keyboard the operator inputs the setpoints for control and alarm limits. The operator then places the system in operation under automatic control. On the next scan, the PLC polls the $\mathrm{PC}$ and recognizes that a change has been made to the setpoints. It loads the new data into the Driver Image Table. This Driver Image Table will be discussed in greater detail in the next section.

The PLC can now take action to increase or decrease the percent output that it requires the SCR to control at. If an example of a heat up is used, the SCR begins to allow a larger pulse width of the input power to pass through to the heaters. Process temperature will begin to increase as sensed by the TE. The PLC updates the Driver Image Table with the new data. It may take further action to control the process if such action is necessary. In any case, the PLC tells the PC that it has updated information. The PC reads the PLC's data registers via the Data Highway Plus (DH+) communication link, and refreshes the operator display screen with the new information. 
To enable a person to more fully understand how data is passed between the PC and PLC, the logicial data model shown below was developed.

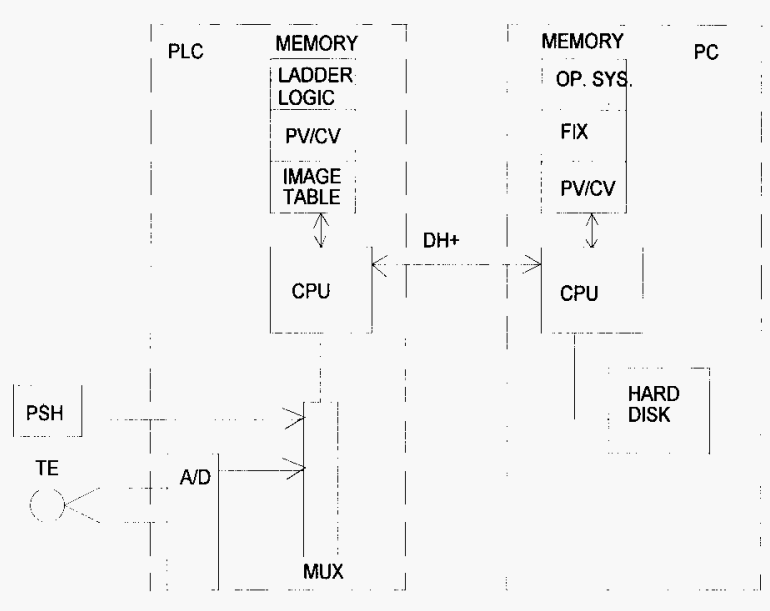

As mentioned before, the PLC takes care of all process signal conditioning such as cold junction compensation, analog to digital conversion, and multiplexing. Its CPU stores data in a Driver Image Table (abbreviated Image Table above) which the PC's CPU can also retrieve to display the Process Variables. The PC and PLC still communicate via the Allen Bradely Data Highway plus via communication protocol called Polling. Appendix F in the SCL500'TM Instruction set manual talks about the PLC file structure in greater detail.

\subsection{Decomposition Description}

\subsection{Module Decomposition}

Not applicable, since this software is a bundled proprietary software and providing the source code was not a condition of the contract.

\subsection{Concurrent Process Decomposition}

The program that acutally controls the process is the Ladder Logic programs for the PLC. Because our system needed to have two CPUs to run the system, the Ladder Logic program when printed out is devided into Device 1 and Device 2. The I/O devices located in Racks 1 and 2 (as numbered from top to bottom) are controlled by Device 1 code and racks 3 and 4 and controlled by Device 2. 
At this time it would be worthwhile for the reader to study chapters 4,6 , and 7 of the Rockwell APS ${ }^{\text {TM }}$ User Manual to be able to understand what the different symbols and comments on the ladder logic mean. Since may of the control rungs on the ladder logic contain PID loops, it is also extremely important to read chapter 9 of the Allen Bradely SLC500 ${ }^{\mathrm{TM}}$ Instruction Set Manual. Another important document is HNF-SD-FF-CSWD-60, the SSF Trace Heat Cross Reference. This document start as one of the self documenting features of the Rockwell APS software, but had to be modified to show how the PLC device numbers correspond to the SCADA Tag Names. This document was created to enable the programmer to determine which ladder rung performs which function. This information is sorted by the PLC input and output $(\mathrm{I} / \mathrm{O})$ addresses. This information will be necessary in order to make any changes that may be required to improve system operation. More information on this topic will be provided in section 3.3 below.

As described in section 2.2, the PLC gathers data from sensors in the field and stores that information in the Driver Image Table. The lead field in the data base is the device Tag Name. Go to rung 2:42 for an example. At this rung TC110A1 is read by the PLC and stored. The value of this register (Source $A$ ) is added to a register that will be used for calculating the zone average (Source B). Then in rung 2:43, the greater than function is used to make sure that the value is valid, if it is not then a valid low value is moved into the source A register. This is a fairly good representation of how the ladder logic in our application flows.

The PLC ladder logic is built in sections. For device 1 the first rungs, numbers $2: 0$ through 2:39 initialize the timers for rate checking subroutine calls. Rungs 2:40 through $2: 89$ read in the first two sodium storage tank zone thermocouples. Rungs 2:90 through 2:113 check for TE hardware problems.

Rungs 2:114 through 2:117 read the status of the pressure switches.

Rungs 2:120 through 2:149 perform Out of Range checks on the thermocouples for the first two tanks. If everything checks out, then rung 2:150 unlatches rung 2:15 I which allows rungs 2:153 through 2:157 to calculate an average temperature for the first trace heat zone on the first storage tank. Rungs 2:158 through 2:187 perform the same functions for the remaining zones on Tank \#1 and Tank \#2.

Rung 2:190 is a very long rung that performs a heatup rate check for the first zone on the first tank. Rungs 2:191 through 2:197 check to make sure that the operator has allowed the PLC to control heat up in automatic/PID mode for the first zone on the first tank. Rungs 2:198 through 2: 236 perform the same functions for the remaining zones on Tank \#1 and Tank \#2.

At this point the duplication becomes even more repetitive. Rungs 2:241 through $2: 431$ (section \#2) perform the same functions for tanks 3 \& 4 that Rungs 2:40 through 2:236 did for tanks one and two.

And rungs 2:434 through 2:809 perform similar functions for the piping trace heat zones.

Rungs 2:810 through 2:911 provide an interlock that makes sure that no more two tanks trace heaters are enegized at the same time. This is because the incoming power supply is sized to handle only the real power load for two tanks, the piping trace heat, and auxilary building loads at any one time. 
The ladder logic for PLC \#2 is also very similar to Device \#1 up to rung 2:451. At this point, the ladder logic sets up heat up rate checking and the individual Proportional, Integral, and Derivative process control blocks. Chapter 9 in the SLC $500^{\mathrm{TM}}$ Instruction Set manual explains the PID control concept and how these ladder blocks perform their control functions. The first block just sets up the tag names that are going to be used as Process Variable and Control Variable. Control Block length is set at the default value of 23 . The Scale (SCL) block multiplies the control variable by the predetermined rate, rounds the value off and adds this value to the offset to determine the pulse width value for firing the SCRs.

Finally rungs $3: 1$ to $3: 107$ are used to down load the PLC configuration to provided by the CPU to each $\mathrm{T} / \mathrm{C}$ module.

\subsection{Data Entity Decomposition}

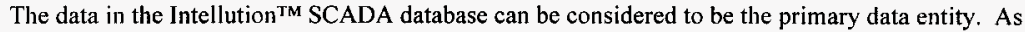
mentioned in section 2.0, this database begins life as spreadsheets in an EXCEL workbook. These spreadsheets are compiled into what appears to be a two dimensional database. When the PC and PLC are interconnected, then this database is updated with information from the PLC. A detailed description of how the PLC handles data is provided in Appendix F of the SLC500 ${ }^{\mathrm{TM}}$ Instruction Set Manual. When looking at the completed database it is difficult to tell where the preprogrammed data ends and the process data begins. For this reason the SSF Trace Heat Cross Reference was created.

HNF-SD-FF-CSWD-60, SSF Trace Heat Cross Reference, gives the programmer the ability to tie the database Tag Name, Tag Type, Trace Heat zone or location, PLC Device designator, PLC I/O module, Ladder Logic Function, and Ladder rung number all together. Without this tool it is difficult to make changes to a specific device without studying all of the reference manuals and entire process to determine how the two programs even work together.

A problem encountered during the facility readiness review prompted plant personnel to learn how this database was constructed. The basic problem was that the reading and alarm functions for two thermocouples were swapped in the database. The system was wired per print because of the fact that when the TE was disconnected from its terminal block, the correct hardware alarm light emitting diode (LED) on the PLC I/O module went into alarm, but the alarms and temperature readings on the computer were wrong. To correct the problem, all that was required was to change the PLC device addresses.

Pages 1 through 5 and pages 101 through 107 setup the labels for the PLC Device numbers in the SCADA database.

From this point on the programmer must refer to Appendix $\mathrm{E}$ in the SLC500 ${ }^{\mathrm{TM}}$ reference manual. Addresses starting with the letter " $B$ " are binary type address locations. Addresses starting with the letter "I" are input address locations. Addresses starting with the letter " $N$ " are Integer type address locations, and so forth.

We don't get into the information that is the most useful to the system analyst until pages 38 for Device \# 1 and page 132 for device \# 2. The pages in the cross reference at this point have been modified from what was produced by the Rockwell APS software. Using MS EXCEL I copied and reviewed the spreadsheets that were used to create the SCADA database. I reduced the number of columns in these spreadsheets to four. These columns contained the Tag Name, the Tag Type, the Trace Heat Zone Description, and the PLC Device address. We added two extra columns for PLC I/O Device number and Ladder Logic Rungs. 
In the cross reference the first field (column) is the Tag Name. The tag name always corresponds in some way to the Trace Heat Zone, TE, or output device designation. For example, for Trace Heat Thermocouple TE- $110 \mathrm{~A} 1$, the data base tag name is $\mathrm{C} 110 \mathrm{~A} 1$. For the average temperature of all for TEs in zone $110 \mathrm{~A}$ the tag name is AV110A.

The second column in the cross reference is the Tag Type was discussed back in section 2.0 of this appendix to the SDD.

The third field is entitled description. In the cross reference, this field is modified from the description in the working database to more accurately identify the alarm or device that is affected. This field still contains an abreviation for what type function this tag performs. For example, the temperature setpoint that is input by the operator is stored under Tag Name SET 110A, and the description used to say just; "SET POINT ADJUST" but it now say's; "TYI 10A SET POINT ADJ."

The fourth column is the PLC Device address, which was also discussed back in section 2.0.

The fifth column is the PLC I/O location. The first number in this code refers the PLC rack in C-3005 numbered 1, 2, 3, \& 4 for the top to bottom as shown back on page 11 . The letter designates the slot in the PLC rack lettered from A positioned from the left (the slot closest to the power supply module) to $M$ located on the right hand side of the rack. The second number indicates the lead terminal or channel number that the sensor wiring is connected to on the PLC. This code also appears in SSF equivalent of the FFTF Trace Heat Index which appears as schedules 4 and 5 of the SSF Trace Heat Vendor information file.

And finally the sixth column indicates they type of arithmetic or logic function and the rung number in the PLC ladder logic program that is associated with this device.

\subsection{DEPENDENCY DESCRIPTION}

\subsection{Intermodule Dependencies}

The Intellution FIX ${ }^{\mathrm{TM}}$ SCADA software is dependent on the PLC ladder logic to retrieve information from the process. The ladder logic cannot be created or modified without the Rockwell Interchange ${ }^{\mathrm{TM}}$ software. The Intellution ${ }^{\mathrm{TM}}$ software is also dependent on the Microsoft DOS and Windows $\otimes$ for its operating environment and Graphical User Interface. Microsoft EXCEL is imbedded in the Intellution ${ }^{\mathrm{TM}}$ software. The Allen Bradley Data Highway Plus software is stored in the directory named "KT" and its associated subdirectories.

The Intellution ${ }^{\mathrm{TM}}$ software is also protected by a hardware key that must be plugged into the PCs parrallel port between the PC and the printer cable. Without this key the system will only operate for two hours in Demo mode.

\section{Interprocess Dependencies}

The PLC ladder logic files are binary files located in the "C:IRSIVIC\BIN" directory. The control data base is called "SODIUM.PDB" and is stored in the "C:IWDMACS\PDB" directory. The spreadsheet file used to create "SODIUM.PDB" is called "SODIUMA.XLS" and is also stored in the "C:IWDMACS\PDB" directory.

The process graphic files are stored in the "C:IWDMACS $\backslash$ PIC" Directory. The Overview screen is called "MAIN_SCR.ODF." The header screeen is named "HEADER.ODF." Each of the Tank, Tank Pair, Setpoint, and TE_OUT screens also have their own ".ODF" files.

$$
\text { HNF-SD-FF-SDD-002 Rev. } 0
$$


Data generated by this software is most easily viewed using the Historical Display software bundled with the Intellution ${ }^{\mathrm{TM}}$ software package. But the raw process data that is used to produce these graphs can also be exported as an ASCII text, a SQL compatible data base file, or an EXCEL spreadsheet. This data will then also require a text editor, word processor, data base management system, or spreadsheet program to view and manipulate that data.

\subsection{Conversion Dependencies}

For information on exporting data see the Intellution ${ }^{\mathrm{TM}}$ Historical Trending Manual for this information.

\subsection{INTERFACE DESCRIPTION}

\subsection{Module Interface}

Taken care of by Intellution ${ }^{\mathrm{TM}}$ when they bundeled their software package.

\subsection{Process Interface}

\section{The SSF custom configured VIEW Control Screens}

The system is broken down into sections. Individual tanks and the main header piping and valves represent the (5) five main sections with each being broken into subsections:

System View with all thermocouple readings for the tank and associated piping and valves up to the header system
Alarm setpoints
Heater setpoints
Trends

The other two sections of the system are the tank pair screens and the Generic Trends screen.

The view screens used in this system have two purposes; monitoring and control with control being limited to a small subset of screens. All screens act as alarm screens since alarms for a particular section are sent to the push buttons for a particular section. If either PLC loses communications with the SCADA system, Large Red Flashing words stating PLC xx Has Lost Communications! is displayed on each screen in the package.

The main screen of the system, OVERVIEW, gives an isometric view of the piping and valves up to the tank tops. All thermocouple alarms can be seen at the screen, this is strictly a monitoring screen as no system control can be initiated from this screen. This screen is the launching point to any other screen available to the system.

The Tank 3001-3004 and Header screens give an overview of the tank along with associated piping and valves. The temperature of each thermocouple is on this screen along with any alarming associated to this section.

There are three main alarm conditions given to this picture.

If a TE temperature is above or below the alarm setpoint value, the temperature value of the TE flashes red. When in tolerance the temperature is displayed as black text.

$$
\text { HNF-SD-FF-SDD-002 Rev. } 0
$$


If the value of a thermocouple reaches a 125 degree spread from its counterparts, it is determined out of range and the first brick in the table, under range, flashes red. If all is well, the brick is green.

If there is a problem with the PLC hardware monitoring the thermocouples, the brick under HDW will flash red. Green indicates all is well.

Other options from this screen allow access to the alarm or heater setpoint screens, the thermocouple take-out screen and trending screens for a particular section.

The Alarm Setpoint Screens allow adjustment of the High and Low alarm setpoints as well as monitoring of high and low alarms, range alarms and hardware alarms for the particular section being manipulated.

The Heater Setpoint Screens have monitoring and control functions utilizing a bank of five boxes which have the following purpose.

The top button is PID ON/OFF this is a push-button which turns a heater zone on or off. When ON, the button indicates PID ON and is lime-green. When OFF, the button indicates PID OFF and is baby blue.

The next button is AUTO/MANUAL. In AUTO mode the button is lime-green and indicates AUTO. When the system is in auto mode a temperature setpoint is entered at the setpoint button. The system automatically move toward the setpoint value while being automatically rate-limited, the percent of power the heater is indicated in the OUTPUT button. In MANUAL mode the button is Yellow and indicates MANUAL. When the system is in manual mode a value from 0 to $100 \%$ is entered at the OUTPUT button, the system applies the amount of output power to the heater until a different value is given. The system requires close monitoring in MANUAL mode since rate-limiting is not applied in MANUAL mode.

The next button is TEMP. This the AVERAGE Temperature of the zone and is for monitoring purposes only.

The next button is Setpoint. When the mouse arrow is placed over the word Setpoint, a small box highlights the word and allows numeric entry of a setpoint value (up to 450 degrees. Setpoint is only valid in AUTO mode.

The last, bottom, button is Output. When the mouse arrow is placed over the word Output, a small box highlights the word and allows numeric entry of a percentage of output power, up to $100 \%$, as desired by the operator to energize the heater.

The TE OUT screen allows the removal of individual thermocouples from the Temperature Averaging routine in the PLC. A thermocouple that is in the system indicates TE_IN and has a red button face. A thermocouple that is out of the system indicates TE_OUT and has a green button face. A TE_OUT is also indicated on the Overview, Tank, Header, and Alarm setpoint screens as a out of range flashing red brick.

The Tank Pairs button takes the operator to tank pair menu from which a desired tank pair can be selected. The tank pair picture contains two tanks with their associated piping and valves. This screen allows monitoring of the average zone temperatures of the selected sections only.

HNF-SD-FF-SDD-002 Rev. 0

Page 32 
Trends allows Temperature vs. Time line charts for the different sections. The information displayed from the trend screen can be historical, up to 30 days, or real-time when a sampling clock is set to give 1,2 or 5 minute updates to the information being displayed. The information being displayed on any given chart will be determined at a later time.

All screens allow the operator to conveniently travel to the main screen sections with the simple click of a mouse. 


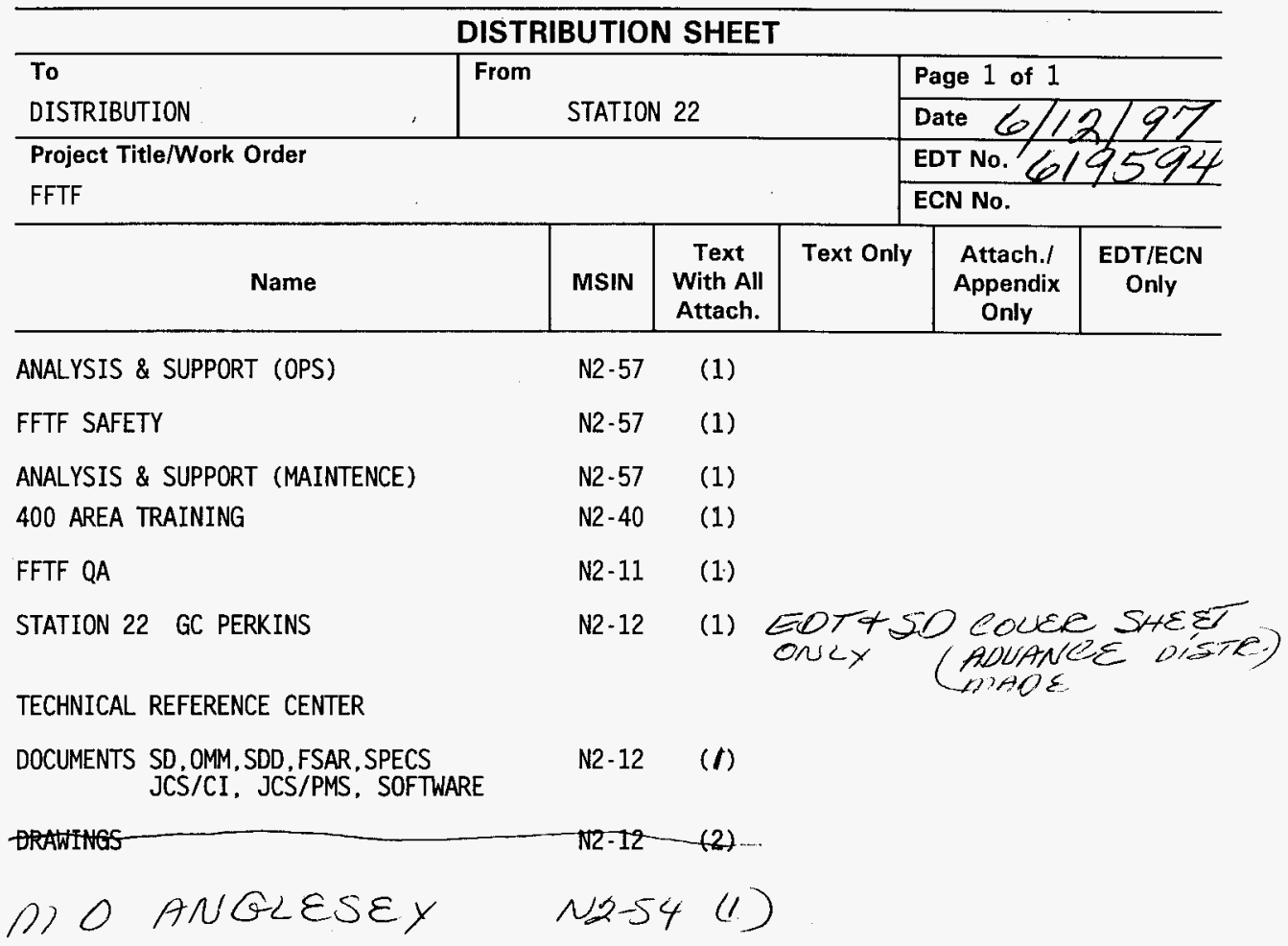

